\title{
EFFECTS OF MARKET ORIENTATION AND BREAKTHROUGH INNOVATION ON ORGANIZATIONAL PERFORMANCE OF INTERNATIONAL ENTERPRISES
}

\author{
Zaixu ZHANG ${ }^{1}$ - Chunqing JIN ${ }^{2}$ \\ ${ }^{1}$ School of Economics and Management, China University of Petroleum (Huadong), \\ No. 66, Changjiang West Road, Huangdao District, Qingdao, China, 266580 \\ ${ }^{2}$ School of Economics and Management, China University Of Petroleum (Huadong), \\ No. 66, Changjiang, West Road, Huangdao District, Qingdao, China, 266580. \\ E-mail: bzhiwsmd@qq.com (corresponding author)
}

\begin{abstract}
In the economic growth process when China joined in WTO, internationalized operation has become an inevitable issue. Under the new normal economic condition, including the cut off tariffs on imported goods, businesses in China have realized the importance of enhancing the overall brand image, quality of products and services, and the international compatibility. Businesses of China need to develop creative and high-value-added products, and shall be able to rapidly change to satisfy market requirements to distinguish themselves from other products. It is the way of creating a new pattern of upgrading. It is the market-orientated development that is a primary condition for enterprises to adapt to the rapidly changing environment, keeping growth and attracting customers, acquiring competitive advantages, and creating excellent value for customers. It reveals the fact that in the future, businesses must change the focus from product to market needs. It is the marketorientation which could generate the competitive strength to resist competitors.

The research involves in total 45 international enterprises, which are distributed with the questionnaires. There are totally 124 and 107 copies of questionnaires retrieved from manufacturing industry and service industry, with valid retrieval rates of $54 \%$ and $46 \%$, respectively. The research results show that: 1 . there is positive effect of market orientation on breakthrough innovation, 2. there is positive effect of breakthrough innovation on organizational performance, and 3. there is positive effect of market orientation on organizational performance. Based upon the results, some suggestions are proposed in this study, expecting to help international enterprises develop market orientation, enhance breakthrough innovation, and improve organizational performance.
\end{abstract}

Keywords: international enterprises, market orientation, breakthrough innovation, organizational performance 


\section{INTRODUCTION}

There are many Chinese enterprises that are keeping the same pace of growing as China's opening and reform progress. By stable steps, many of them grew to be large business groups within decades, and the business size and scale were enlarged with the equivalent strength to conglomerates. When joined in WTO, internationalization became an inevitable issue; natural resources are short compared with the economic size. Nevertheless, especially, the emergence of South East Asia and India resulted in China based international businesses largely transferring to the regions with capitals, technologies, and equipment, causing the declination of a lot of industries. Even though China is still having the crown of "the world's second largest economy", in general China's businesses are large but weak. There is an urgent need to upgrade in lots of industries, which is having problems such as lack of innovation, lack of critical and core technologies, low level of quality, very few world famous brand, irrational industrial structure, overcapacity of traditional industry and insufficient supply of emerging industry, low level of internationalization, low ability of global management; production resource supply is reaching their maximum limit.

The downturn in the world economy and the deterioration of the internal and external business environment continues and let Chinese companies recognize that they should enhance the overall quality of image and international competitiveness, enhance the overall brand image, quality of products and services, and the international compatibility. Businesses of China need to develop creative and high-value-added products, and shall be able to rapidly change to satisfy market requirement to distinguish themselves from other products. It is the way of creating a new pattern of upgrading.

The cause of Chinese enterprises' long life cycle relies mainly on the continued growth energy. During the past decades, the economic environment in China evolves from poverty to today's prosperity. Apparently that brings large development space. Perhaps it is fair to claim that the whole background time provides conditions for survival and development. However, in order to avoid the dilemma of "the scale of today is tomorrow's burden", the motivation of continued growth is the method of survival and development for large group enterprises. And the source of the growth momentum is nothing more than the expansion of the original business scope, diversified market (entering into new markets), as well as access to international markets, etc. When we look back at the path of development of China's enterprise group, it is not difficult to find its growth pattern: at the early stage, in order to focus on the consolidation of the core competitive advantage, and gradually, along with the formation of enterprise resources, they start the diversification of mobile resources and international marketing endeavor. In 
order to adapt to the rapid changes in the business environment, one of the many managers and scholars have been closely paying attention to how to develop and maintain their customers and the market. In many modern marketing literatures we agree that how the enterprises obtain the competitive advantage and create superior customer value and indispensable conditions is the establishment of market orientation. Current enterprises no longer stress on short-term sales performance, but emphasize to establish and maintain good relationship with customers. The concepts of database marketing, relationship marketing, and market orientation are therefore emerged, revealing that future enterprises would change from product orientation to customer-centered market orientation, which could generate competitive strengths to resist competitors.

\section{DEFINITION AND HYPOTHESIS DERIVATION}

\subsection{Market orientation}

Abebe and Angriawan (2014) defined market orientation as "the abilities of an organization generating, propagating, and utilizing customer and competitor correlated information". According to above market orientation elements, Azizi et al. (2009) developed a questionnaire to measure the market orientation of enterprises. The questionnaire allowed researchers actually measuring the behavior of an enterprise taking market orientation, rather than halting market orientation for a belief and slogan. From the past research on market orientation, the definitions of market orientation could be divided into two categories, according to the contents proposed by Green et al. (2012). The former was redefined and included in a new dimension by successive researchers from the aspect of organizational learning (Kim and Atuahene-Gima 2010), as the market information processing discussed in the following section. The latter discussed the definition of market orientation based on organizational culture (Meyer 2011) and was regarded meaningful, because organizational culture presented the common value to regulate organizational members' behaviors, and integrating market orientation into organizational culture could ensure organizational members performing the market orientated behaviors (Shang et al. 2010; Keszey 2011). Furthermore, Wu (2013) defined market orientation as "measuring market orientation from culture". The definition in this study is therefore referred to Abebe and Angriawan (2014) in order not to confuse with the complete market orientation idea. Azizi et al. (2009) indicated that both market oriented culture and market information processing had to be covered in order to completely measure market orientation (Kim and AtuaheneGima 2010). In regard to cultural market orientation, the dimensions proposed by 
Abebe and Angriawan (2014) are utilized in this study, and long-term view and profitability are deleted, because most researchers merely applied customer orientation, competitor orientation, and interfunctional coordination to the research (Meyer 2011). Such three dimensions are therefore used for measuring market orientation in this study.

(1) Customer orientation - an enterprise has to understand target buyers till to continuously create excellent value for them.

(2) Competitor orientation - an enterprise has to understand the long-term and short-term advantages \& drawbacks, abilities, and strategies of present or potential key competitors.

(3) Interfunctional coordination - the corporate resources are integrated to create excellent value for buyers, according to customer and competitor information and the coordination and cooperation between departments, including marketing department, in an enterprise.

\subsection{Breakthrough innovation}

Innovation is defined to generate or accept new ideas, new processes, new products, or new services; anything that allows people perceiving "new" is called innovation (Adler et al. 2009). Early research discovered that the higher originality of new products could provide higher value (Cheng and Krumwiede 2012). Innovation covers management, technology, product, and process (Hsu and $\mathrm{Hu} 2011$ ). According to distinct perceived newness of customers or enterprises, innovation could be divided into incremental innovation and breakthrough innovation. The former refers to minor changes in technologies or products, which appear limited improvement on corporate performance. The latter is a kind of novel, unique, and state-of-the-art technological innovation, which presents great effects on current products and could change current consumption habits (Leiponen and Helfat 2010). Both technological innovation and market innovation achieve innovation from the aspects of technology and market. In regard to technology, technological innovation generally refers to state-of-the-art advance on technologies (Ngo and O'Cass 2012), while market innovation does not necessarily need state-ofthe-art advance on technologies, but merely uses a simple technology to achieve market innovation (Shi et al. 2012). In terms of market, technological innovation stresses on providing new technologies with better value of present products to satisfy current market demands (Wu et al. 2012); market innovation, on the other hand, focuses on designing a new product for the required new value in a new market (Sebrek and Garrido 2015). In other words, a new value is introduced to destroy present customer preference structure (Leiponen and Helfat 2010). 
Cheng and Krumwiede (2012) and Hsu and $\mathrm{Hu}$ (2011) agreed with the differences between market innovation and technological innovation as technological innovation was measured by the difficulty of technology, while market innovation needed to understand and evaluate new products with new value for the mainstream customers of present products as well as the acceptance of such new products.. Accordingly, Cheng and Krumwiede (2012) developed the measurement questionnaires for market innovation, which are applied to measure breakthrough innovation in this study.

\subsection{Organizational performance}

Aiming at past research on consequences of market orientation organized by Armstrong and Kotler (2012), four common subjective performance indicators are used for measuring market orientation.

(1) Organizational performance. Organizational performance contains cost-based performance, revenue performance, and the comparison between a manager's subjective cognition of the organization and the competitor performance, or the comparison between strategic effectiveness and preset objectives (Chiou et al. 2011).

(2) Customer consequences. Customer consequences refer to the quality, loyalty, and satisfaction of customer cognition about products or services offered by an organization (Hsu and Sabherwal 2011).

(3) Innovation consequences. Innovation consequences include the innovation ability of an organization, i.e. the ability of an organization executing new ideas, new products, and new processes (Lin et al. 2013), and new product performance, i.e. the measurement of market share, sales volume, return on investment (ROI), and profitability of new products ( $\mathrm{O}^{\prime}$ Cass and Weerawardena 2010).

(4) Employee consequences: Stock and Zacharias (2013) indicated that market orientation could gradually implant some dignity and loyalty to employees in order to reinforce the organizational commitment, esprit de corps, customer orientation, and job satisfaction.

Yannopoulos et al. (2012) used the subjective indicators of market effectiveness and rate of asset (ROA) calculated from financial statement for evaluating organizational performance. Lin et al. (2013) applied organizational performance and product performance, such as sales growth and product quality, to measure performance. Hsu and Sabherwal (2011) considered that a market-oriented enterprise could establish good relationship with customers by understanding market demands and developing unique market view. Apparently, customer responses 
are important for an organization. Customer consequences organized by Hsu and Sabherwal (2011) and market effectiveness proposed by Armstrong and Kotler (2012) are utilized in this study for measuring organizational performance from the aspects of customer and market.

\subsection{Hypothesis inference}

A market-oriented organization cannot appeal customers to purchase the products or services. As a matter of fact, understanding customer demands by motivating employees and allowing employees taking the most appropriate responses are the keys in an organization promoting market orientation to appeal customers (Askarany et al. 2010). Dao et al. (2011) pointed out the output of customer orientation, competitor orientation, and interfunctional coordination in market orientation being able to assist an organization in acquiring complete market intelligence and thoroughly understanding the markets. For an organization, customers' expressed needs were apparent, while the latent needs could hardly be found (Hsu and Wang 2012). "Lead-users" could reinforce the ability of an organization understanding the customers' latent needs. Such a skill could help an organization finding out "lead-users" which were not sensitive to unsatisfied demands; the organization would develop new technology for such lead-users and allow them finding out new solution for those unsatisfied demands ( $\mathrm{Li}$ and Zhou 2010). Focusing on latent needs is an organization considering future demands from present customers and allows the organization considering the possible actions of competitors for cultivating the organizational technological innovation (Sarkis et al. 2011). It is therefore inferred that

H1: Market orientation presents positive effects on breakthrough innovation.

Researchers with dynamic capabilities indicated that competitive advantages could not be continued in modern markets, and organizational performance was established on discontinuous competitive advantages (Terawatanavong et al. 2011). Zhou et al. (2012) pointed out the introduction of breakthrough innovation as the survival of an organization in the turbulent environment, where breakthrough innovation contained technology and market innovation, presented the potential to create markets, built consumer preference, and changed consumption habits. When breakthrough innovation was practiced, consumer dependence on such innovation would be largely enhanced and even had consumers perceive "how to continue life without it" (Hsu and Wang 2012). Cheng and Krumwiede (2012) particularly pointed out the factors in the contribution of breakthrough innovation to organizational performance. Technological innovation could rein- 
force the present value of major customers of an organization in order to promote organizational performance. Abebe and Angriawan (2014) also pointed out the significant effects of breakthrough innovation on organizational performance. It is therefore inferred that

$\mathrm{H} 2$ : Breakthrough innovation reveals positive effects on organizational performance. Stock and Zacharias (2013) mentioned that market orientation could have an organization pay attention to market conditions, allow the organization paying attention to customer ideas and related knowledge to find out the ability of an organization creating value for customers, and enhance organizational performance (Ngo and O'Cass 2012). Wu (2013) indicated that an organization with marketoriented culture should understand the evolution of customers so as to develop innovative solution aiming at such demands (Cheng and Krumwiede 2012). In fact, an organization with high market-oriented culture would pay attention to expressed needs and latent needs and emphasize knowledge which could create value for customers. In this case, it could better explore and find out customers' latent needs, and draw hidden new value for organizational performance (O'Cass and Weerawardena 2010). It is therefore inferred in this study that

H3: Market orientation shows positive effects on organizational performance.

\section{DESIGN OF RESEARCH METHODOLOGY}

\subsection{Operational definition and measurement of variable}

\subsubsection{Market orientation}

Market orientation is divided into three dimensions of customer orientation, competitor orientation, and interfunctional coordination, whose scales are referred to Abebe and Angriawan (2014). The total reliability coefficients of customer orientation, competitor orientation, and interfunctional coordination show 0.84 , 0.87 , and 0.81 , respectively.

\subsubsection{Breakthrough innovation}

Breakthrough innovation is divided into market innovation and technological innovation, whose scales is referred to Cheng and Krumwiede (2012). The total reliability coefficients of market innovation and technological innovation reveal 0.83 and 0.85 , respectively. 


\subsubsection{Organizational performance}

Organizational performance is classified into market innovation and technological innovation, whose scales are referred to Hsu and Sabherwal (2011) and Armstrong and Kotler (2012). The total reliability coefficients of customer consequences and market effectiveness show 0.89 and 0.82 , respectively.

\subsection{Research participant}

The questionnaire participants are selected from traditional manufacturing industry, hi-tech manufacturing industry, and service industry. Improper participants are deleted from the database, and the answering of questionnaires is explained in advance. Financial industry and nonprofit organizations are removed that total 45 international enterprises are distributed the questionnaires. Total 124 and 107 valid copies of questionnaires are retrieved from manufacturing industry and service industry, with the retrieval rate $54 \%$ and $46 \%$, respectively. The participants are set R\&D personnel; when the participants are not $R \& D$ related personnel, department managers, e.g. assistant vice president, are selected for answering the questionnaires. The database selection and the explanation before the questionnaire survey tend to ensure the qualification of participants.

\subsection{Verification of reliability and validity analyses}

The research dimensions achieve above 0.7 , showing the high reliability. The construct validity is analyzed by Confirmatory Factor Analysis. See Table 1, both convergent validity and construct validity of the scales in this study are the favorable.

Table 1. Confirmatory factors

\begin{tabular}{l|l|l}
\hline Research dimension & \multicolumn{1}{|c}{ Total fit } & \multicolumn{1}{c}{ Analysis } \\
\hline Market orientation & $\begin{array}{l}\mathrm{X} 2=0(\mathrm{P}<0.001) ; \mathrm{DF}=0 ; \mathrm{GFI}=1.00 ; \\
\mathrm{CFI}=1.00\end{array}$ & excellent overall model fit \\
\hline $\begin{array}{l}\text { Breakthrough in- } \\
\text { novation }\end{array}$ & $\begin{array}{l}\mathrm{X} 2=0(\mathrm{P}<0.001) ; \mathrm{DF}=0 ; \mathrm{GFI}=1.00 ; \\
\mathrm{CFI}=1.00\end{array}$ & excellent overall model fit \\
\hline $\begin{array}{l}\text { Organizational } \\
\text { performance }\end{array}$ & $\begin{array}{l}\mathrm{X} 2=0(\mathrm{P}<0.001) ; \mathrm{DF}=0 ; \mathrm{GFI}=1.00 ; \\
\mathrm{CFI}=1.00\end{array}$ & excellent overall model fit \\
\hline
\end{tabular}




\section{ANALYSIS}

\subsection{Correlation analysis}

From Table 2, market orientation, breakthrough innovation, and organizational performance reveal remarkable correlations. Such results show the multicollinearity among dimensions. Niehoff and Moorman (1993) therefore suggested that a researcher could use Nested Model Analysis to solve such problems. Besides, the notable correlations among dimensions also reveal the match with the researcher's hypotheses.

Table 2. Correlation analysis

\begin{tabular}{|l|c|c|c|c|}
\hline Research dimension & $\alpha$ & Market orientation & $\begin{array}{c}\text { Breakthrough } \\
\text { innovation }\end{array}$ & $\begin{array}{c}\text { Organizational } \\
\text { performance }\end{array}$ \\
\hline Market orientation & 0.85 & & & \\
\hline $\begin{array}{l}\text { Breakthrough } \\
\text { innovation }\end{array}$ & 0.87 & $0.42^{* *}$ & & \\
\hline $\begin{array}{l}\text { Organizational } \\
\text { performance }\end{array}$ & 0.92 & $0.37^{* *}$ & $0.53^{* *}$ & \\
\hline
\end{tabular}

Note: $* *$ stands for $\mathrm{p}<0.01$.

\subsection{Discussion of theoretical model}

The research results in this study are shown as following. Significant path coefficients are denoted with solid lines, while the ones not reaching the significance are denoted with dotted line. Obviously, the path coefficients of all variables achieve the significance, showing those coefficients reaching the convergent validity, which is the basic requirement for the model analysis. The theoretical model fits, $\mathrm{GFI}=0.962, \mathrm{AGFI}=0.937, \mathrm{RMSEA}=0.06$, and $\mathrm{CFI}=0.983$, verify the model fit that this research model conforms to the theory and presents validity.

\subsection{Discussion of research hypothesis}

The research hypotheses are tested with Nested Model. Chi-square test of difference is utilized as each Nested Model appears the difference of one degree of freedom. Accordingly, when the deduction of chi-square value in Nested Model and the chi-square value in the theoretical model achieve the significance, the path coefficient being set 0 is remarkable. The research results show the notable model; the results of Nested Model analysis are shown in Table 3; and the hypothesis verification is displayed in Table 4. 


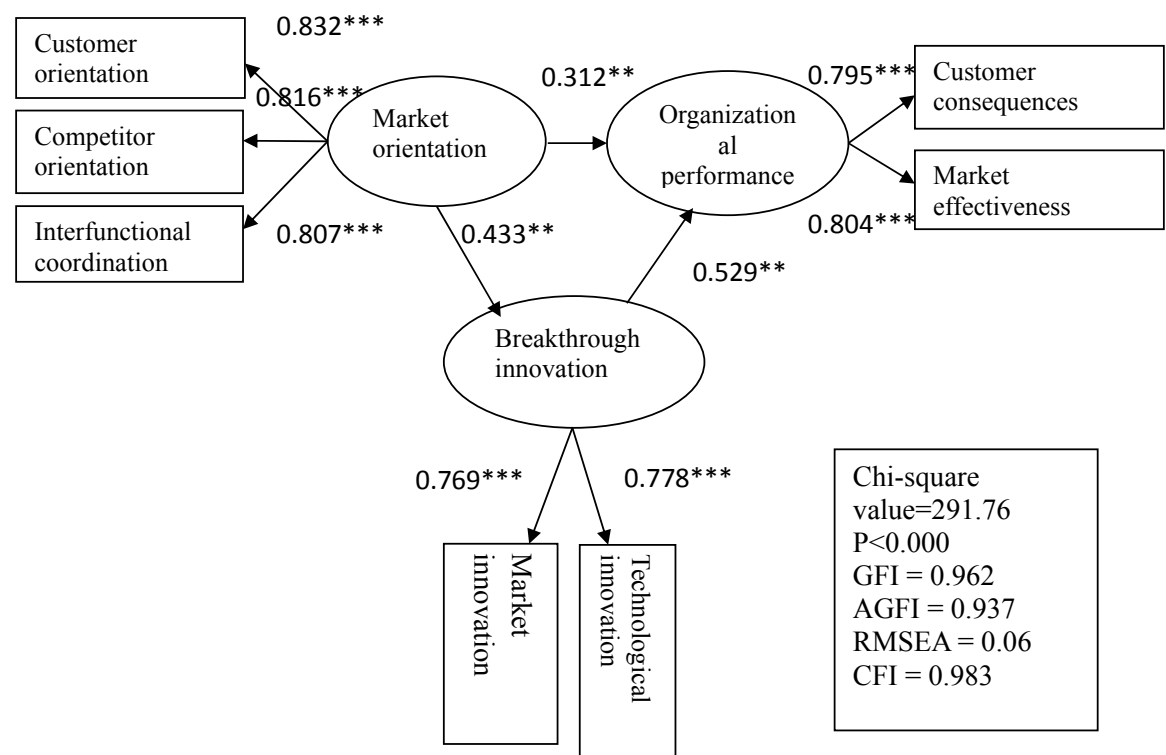

Figure 1. Path diagram

Note: ${ }^{* *}$ stands for $\mathrm{p}<0.01,{ }^{* * *}$ for $\mathrm{p}<0.001$

Table 3. Nested Model analysis

\begin{tabular}{|c|c|c|c|c|c|}
\hline Model & $\chi^{2}$ & $\Delta \chi^{2}$ & GFI & CFI & RMSEA \\
\hline Theoretical model & 291.76 & & 0.962 & 0.983 & 0.06 \\
\hline $\begin{array}{l}\text { Model 1: hypothesis } \\
\text { verification }\end{array}$ & 297.19 & $5.43 *$ & 0.962 & 0.983 & 0.06 \\
\hline $\begin{array}{l}\text { Model 2: hypothesis } \\
\text { verification }\end{array}$ & 303.31 & $6.12 *$ & 0.962 & 0.983 & 0.06 \\
\hline $\begin{array}{l}\text { Model 3: hypothesis } \\
\text { verification }\end{array}$ & 307.88 & $4.57 *$ & 0.962 & 0.983 & 0.06 \\
\hline
\end{tabular}

Note: * stands for $\mathrm{p}<0.05$

Table 4. Hypothesis verification

\begin{tabular}{l|c|c|c|c}
\hline Research hypothesis & Correlation & $\begin{array}{c}\text { Experimental } \\
\text { result }\end{array}$ & $\mathrm{P}$ & Result \\
\hline Hypothesis 1 & + & 0.433 & 0.00 & supported \\
\hline Hypothesis 2 & + & 0.529 & 0.00 & supported \\
\hline Hypothesis 3 & + & 0.312 & 0.00 & supported \\
\hline
\end{tabular}




\section{CONCLUSION}

According to the statistical analyses, the hypothesis between market orientation and breakthrough innovation (H1) is supported, proving the notably positive effects of market orientation on breakthrough innovation. That is, the higher market orientation could assist the organization in developing breakthrough innovation. From the analyses in this study, market orientation could establish the culture inside the organization to understand the market and to enhance the organization developing breakthrough innovation based on such understanding. Besides, it allows the organization promoting the capital commitment to innovation and enhancing the success of innovation research and development which requires huge capitals. Based on the statistical analyses, the hypothesis between breakthrough innovation and organizational performance (H2) is supported, proving the significantly positive effects of breakthrough innovation on organizational performance. In other words, the more successful breakthrough innovation could enhance organizational performance. The research analyses show that the faster changes in technology or consumer preference present the introduction of breakthrough innovation being able to help the outperformance of the organization. The statistical analyses reveal the support on the hypothesis between market orientation and organizational performance (H3). It proves the remarkably positive effects of market orientation on organizational performance. That is, the higher market orientation could promote organizational performance. From the analyses in this study, "understanding culture" established in market orientation could output various information and knowledge related to markets and indeed could enhance organizational development. An organization therefore has to present favorable market-oriented culture basis to well promote the organizational performance.

\section{RECOMMENDATIONS}

Summing up the important results and findings, the following practical suggestions are proposed in this study.

- The notably positive effects of market orientation on breakthrough innovation are proven in this study that international enterprises are suggested to establish culture and activities which continuously concern about market orientation in order to help international enterprises cultivate the sensitivity to market orientation for the development and the improvement of breakthrough innovation. However, it is related to the entire strategic content planning and purpose of an international enterprise that it should promote "concerning market-oriented culture and activities" and actively establish information propagation channels 
between departments, expecting that market-oriented information could be flown among departments in the international enterprise, and the departments could cultivate the sensitivity to market orientation for products and services suitable for market demands.

- This study proves the significantly positive effects of breakthrough innovation on organizational performance. It is suggested that international enterprises could reinforce the development of breakthrough innovation and promote the organizational performance by enhancing the communication frequency with consumers, analyzing competitors, establishing efficient internal information propagation channels between departments, and ensuring the consensus of departments to comprehend the markets.

- This study proves the remarkably positive effects of market orientation on organizational performance that international enterprises are suggested to continuously concern about market-oriented culture and activities and cultivate the sensitivity to market preferences so as to enhance the market responses earlier than the competitors. Information collected from markets and competitors are utilized for investing in the development of breakthrough innovation and planning the accurate strategies and execution; the value is offered for customers who are in need, from correctly and rapidly responding to customers to involving in innovation research and development. It is expected to establish the entry threshold to markets and improve industrial competition so as to enhance profitability.

\section{REFERENCES}

Abebe, M.A. and Angriawan, A. (2014). Organizational and competitive influences of exploration and exploitation activities in small firms. Journal of Business Research, 67, 339-345.

Adler, P.S., Benner, M., Brunner, D.J., MacDuffie, J.P., Osono, E., Staats, B.R. and Winter, S.G. (2009). Perspectives on the productivity dilemma. Journal of Operations Management, 27(2), 99-113.

Armstrong, G. and Kotler, P. (2012). Marketing: An Introduction (11th ed.). Upper Saddle River, New Jersey: Prentice Hall.

Askarany, D., Yazdifar, H. and Askary, S. (2010). Supply chain management, activity-based costing and organizational factors. International Journal of Production Economics, 127(2), 238-248.

Azizi, S., Movahed, S.A. and Haghighi Khah, M. (2009). The effect of marketing strategy and marketing capability on business performance. Case study: Iran's medical equipment sector. Journal of Medical Marketing, 9(4), 309-317.

Cheng, C.C. and Krumwiede, D. (2012). The role of service innovation in the market orientation New service performance linkage. Technovation, 32(7-8), 487-497.

Chiou, T.Y., Chan, H.K., Lettice, F. and Chung, S.H. (2011). The influence of greening the suppliers and green innovation on environmental performance and competitive advantage in Taiwan. Transportation Research Part E, 47(6), 822-836. 
Dao, V., Langella, I. and Carbo, J. (2011). From green to sustainability: Information technology and an integrated sustainability framework. Journal of Strategic Information Systems, 20(1), 63-79.

Green, K.W., Zelbst, P.J. and Bhadauria, V.S. (2012). Green supply chain management practices: Impact on performance. Supply Chain Management: An International Journal, 17(3), 290305.

Hsu, C.W. and Hu, A.H. (2011). Applying hazardous substance management to supplier selection using analytic network process. Journal of Cleaner Production, 17 (2), 255-264.

Hsu, I.C. and Sabherwal, R. (2011). From intellectual capital to firm performance: the mediating role of knowledge management capabilities. IEEE Transactions on Engineering Management, $58,626-642$.

Hsu, L.C. and Wang, C.H. (2012). Clarifying the effect of intellectual capital on performance: the mediating role of dynamic capability. British Journal of Management, 23, 179-205.

Keszey, T. (2011). How market information is transformed into marketing knowledge? Acta Oeconomica, 61(3), 313-336.

Kim, N. and Atuahene-Gima, K. (2010). Using exploratory and exploitative market learning for new product development. Journal of Product Innovation Management, 27, 519-536.

Leiponen, A. and Helfat, C.E. (2010). Innovation objectives, knowledge sources, and the benefits of breadth. Strategic Management Journal, 31, 224-236.

Li, J.J. and Zhou, K.Z. (2010). How foreign firms achieve competitive advantage in the Chinese emerging economy: Managerial ties and market orientation. Journal of Business Research, 63, 856-862.

Lin, R.J., Tan, K.H. and Geng, Y. (2013). Market demand, green product innovation, and firm performance: Evidence from Vietnam motorcycle industry. Journal of Cleaner Production, 40, 101-107.

Meyer, J.P. (2011). Effects of exploration on the relationship between intellectual capital and the retained technical value of innovation. International Journal of Innovation Management, 15, 249-277.

Ngo, L.V. and O'Cass, A. (2012). In search of innovation and customer-related performance superiority: The role of market orientation, marketing capability, and innovation capability interactions. Journal of Product Innovation Management, 29, 861-877.

Niehoff, B.P. and Moorman, R.H. (1993). Justice as a mediator of the relationship between methods of monitoring and organizational citizenship behavior. Academy of Management Journal, 36(3), 527-556.

O'Cass, A. and Weerawardena, J. (2010). The effects of perceived industry competitive intensity and marketing-related capabilities: Drivers of superior brand performance. Industrial Marketing Management, 39(4), 571-581.

Sarkis, J., Zhu, Q. and Lai, K.H. (2011). An organizational theoretic review of green supply chain management literature. International Journal of Production Economics, 130(1), 1-15.

Sebrek, S.S. and Garrido, B.P. (2015). Competitive pressure and technological degree of the product portfolio: Implications for firm performance. Acta Oeconomica, 65(2), 211-229.

Shang, K.C., Lu, C.S. and Li, S. (2010). A taxonomy of green supply chain management capability among electronics-related manufacturing firms in Taiwan. Journal of Environmental Management, 91(5), 1218-1226.

Shi, V.C., Lenny Koh, S.C., Baldwin, J. and Cucchiella, F. (2012). Natural resource based green supply chain management. Supply Chain Management: An International Journal, 17(1), 54-67. 
Stock, R.M. and Zacharias, N.A. (2013). Two sides of the same coin: How do different dimensions of product program innovativeness affect customer loyalty? Journal of Product Innovation Management, 30(3), 516-532.

Terawatanavong, C., Whitwell, G.J., Widing, R.E. and O'Cass, A. (2011). Technological turbulence, supplier market orientation, and buyer satisfaction. Journal Business Research, 64(8), 911-918.

Wu, G.C. (2013). The influence of green supply chain integration and environmental uncertainty on green innovation in Taiwan's IT industry. Supply Chain Management: An International Journal, $18(5), 539-552$.

Wu, G.C., Ding, J.H. and Chen, P.S. (2012). The effects of GSCM drivers and institutional pressures on GSCM practices in Taiwan's textile and apparel industry. International Journal of Production Economics, 135(2), 618-636.

Yannopoulos, P., Auh, S. and Menguc, B. (2012). Achieving fit between learning and market orientation: Implications for new product performance. Journal of Product Innovation Management, 29, 531-545.

Zhou, M., Pan, Y.C., Chen, Z.M., Yang, W. and Li, E.R. (2012). Selection and evaluation of green production strategies: Analytic and simulation models. Journal of Cleaner Production, 26, $9-17$. 